\title{
Democracia y mediatización: aportes para la teoría del caudillaje competitivo de Joseph Schumpeter desde una perspectiva comunicacional
}

\author{
Democracy and mediatization: contributions to the competitive \\ leadership theory of Joseph Schumpeter from a communicational \\ perspective
}

Facundo Rodríguez frodriguez@humanidadesucsf.edu.ar http://orcid.org/0000-0003-4242-4605

Facultad de Humanidades; Universidad Católica de Santa Fe (Argentina)

\begin{abstract}
Resumen
La insatisfacción con la definición clásica de democracia condujo a Schumpeter a su redefinición. Entendido en términos de forma y mecanismo de regulación del ejercicio político nos proponemos comprender la teoría del caudillaje competitivo propuesta por el pensador austríaco profundizando en su dimensión comunicacional. Los aportes de diferentes disciplinas que integran el campo de las ciencias de la comunicación permitirán un nuevo acercamiento a los principales postulados de Schumpeter. Se propondrá al espacio público mediatizado como escenario de disputa por el caudillaje político y se discutirá el proceso de creación de voluntades a partir del concepto de mediaciones. Por último, señalaremos algunos aspectos
\end{abstract}


problemáticos que consideramos deben ser indagados para una comprensión más profunda del funcionamiento democrático.

Palabras Clave: Mediatización de la política; Teoría del caudillaje competitivo; espacio público mediatizado; Joseph Schumpeter.

\section{Abstract}

Dissatisfaction with the classical democracy definition led Schumpeter to its redefinition. Understood in terms of form and mechanism of regulation of the political exercise we propose to understand the competitive leadership theory proposed by the Austrian thinker, deepening in its communicational dimension. The contributions of different disciplines that integrate the communication sciences field will allow a new approach to the main postulates of Schumpeter. The mediated public space will be proposed as the setting for the dispute over political leadership, and the creating wills process will be discussed based on the mediations concept. Finally, we will point out some problematic aspects that we believe should be investigated for a deeper understanding of democratic functioning.

Keywords: Mediation of Politics; Theory of competitive leadership; mediatized public space; Joseph Schumpeter.

\section{Schumpeter y la crítica a la teoría clásica}

Joseph Schumpeter (1984) realiza en Capitalismo, Socialismo y Democracia una exhaustiva crítica a la filosofía política clásica respecto a su definición del método democrático. El autor austríaco condensa los principales argumentos de aquella tradición en la siguiente definición:

El método democrático es aquel sistema institucional de gestación de las decisiones políticas que realizan el bien común, dejando al pueblo decidir por sí mismo las cuestiones en litigio mediante la elección de los individuos que han de congregarse para llevar a cabo su voluntad (1984: 321). 
Esta concepción se erige bajo un cierto número de supuestos que se intentarán reconstruir brevemente siguiendo el hilo argumental del propio Schumpeter. En primer lugar aparece la idea de bien común como elemento orientador de la política. Este es capaz de ser percibido por cualquier hombre a través de la argumentación racional, por lo cual todos estamos inducidos a acordar sobre él. Por otra parte, entre las hipótesis de la teoría clásica emerge la problemática de la representación. La definición de método democrático implica que la dirección de algunos asuntos públicos requiere de saberes especializados que deben ser conferidos a especialistas. No obstante, esta delegación no afecta al principio democrático porque los representantes actúan conforme a la voluntad popular. De esta manera, los individuos deciden sólo sobre cosas importantes a través del referéndum; mientras que los especialistas se encargan de aspectos menores, reflejando, interpretando, representando la voluntad del electorado.

Al aceptar estas hipótesis, señala Schumpeter, el lector se encuentra ante una democracia inequívoca, sin problemas. Pero estas no son más que ideas que deben ser probadas. Y, para el economista austríaco, es más fácil refutarlas:

No hay tal bien común, unívocamente determinado en el que todo el mundo pueda estar de acuerdo o pueda hacérsele estar de acuerdo en virtud de la argumentación racional (...) para los distintos individuos y grupos el bien común ha de significar necesariamente cosas diferentes (...) nuestras concepciones de lo que debe ser la vida y la sociedad están más allá de la mera lógica (...) Aún cuando resultase aceptable para todos un bien común suficientemente definido (...) esto no implicaría respuestas igualmente definidas para los problemas singulares (Schumpeter, 1984: 322-323).

Al no existir un bien común general, no es posible hablar de una voluntad del pueblo. Sin embargo, insiste Schumpeter, aún permanece en la teoría clásica la necesidad de atribuir a la voluntad del individuo un carácter independiente y racional que también es irreal. Bajo la óptica clásica la voluntad del individuo debería ser algo más que vagos impulsos frente a ciertas impresiones o tópicos dados. Todas las personas deberían conocer en modo preciso su interés y ante cada problema dar una respuesta clara, rápida y eficaz, conforme a las reglas de deducción lógica. Este debería ser el comportamiento del ciudadano medio, sin presiones de grupos ni de propaganda.

Para desbaratar esta postura y demostrar la importancia de elementos extra-racionales que guían el comportamiento individual, Schumpeter recurre a los aportes de Gustave Le Bon en Psicología de las multitudes y al estudio de los economistas sobre el comportamiento de los consumidores y la influencia en ellos de la propaganda. Si bien esta última recurre 
esporádicamente a argumentos racionales, la persuasión apunta más bien al subconsciente: parece que los productores crean sus necesidades. Sin embargo, Schumpeter advierte que no es tan fácil engañar a los hombres, puesto que, en general, comprenden bien las cosas que le conciernen directamente. No obstante, cuando las cuestiones políticas no tienen un vínculo directo con las preocupaciones personales, la voluntad individual, el conocimiento de los hechos y el método de inferencia dejan de actuar como lo supone la teoría clásica. Se pierde el sentido de la realidad. El ciudadano tiene la impresión de moverse en un mundo ficticio. El sentido limitado de la realidad explica el sentido limitado de la responsabilidad y el sentido limitado de su voluntad efectiva.

\begin{abstract}
Cada uno tiene, por supuesto, frases propias y deseos e ilusiones y quejas propias, especialmente cada uno tiene sus preferencias y aversiones. Pero ordinariamente esto no corresponde con lo que llamamos una voluntad, esto es, la contrapartida psíquica de una acción responsable y consciente de su finalidad. En efecto: para el ciudadano particular que medita sobre asuntos nacionales no hay lugar para una voluntad tal, ni para ninguna labor que pueda desarrollar (Schumpeter, 1984: 334).
\end{abstract}

En el campo de la política, el ciudadano normal desciende a un nivel inferior de prestación mental, argumentando de manera infantil en comparación con aquellos asuntos que le interesan. Se hace de nuevo primitivo, poseedor de un pensamiento que deviene asociativo y efectivo. En consecuencia, el individuo se deja guiar por sus prejuicios e impulsos extra racionales o irracionales, relajando sus exigencias morales al considerar que la política no es asunto suyo. Incluso, cuanto más débil sea el argumento lógico en la formación política del ciudadano y haya menos visión crítica y responsabilidad, más oportunidades tendrán los grupos de intereses definidos de configurar la voluntad del pueblo, e incluso de crearla. "La voluntad que observamos al estudiar los procesos políticos no es ni con mucho una voluntad auténtica, sino fabricada (...) La voluntad del pueblo es el producto y no la fuerza propulsora del proceso político" (Schumpeter, 1984: 336). Los elementos de su fabricación son similares a la propaganda comercial; en ellos se encuentran esfuerzos por llegar al contacto con lo subconsciente, por crear asociaciones favorables y desfavorables, según la conveniencia, evitando la argumentación racional, que podría despertar el espíritu crítico. Sin embargo, Schumpeter advierte que el uso de estos recursos es más peligroso en el caso de la esfera política. La propaganda comercial puede desenmascararse fácilmente, pero los efectos de la política son más difíciles de interpretar. 


\section{La propuesta teórica de Schumpeter: la democracia como competencia}

La crítica que Schumpeter realiza sobre la teoría clásica resulta la antesala para ofrecer al lector una nueva forma de comprender la democracia. Como hemos visto, los clásicos sostienen que el pueblo tiene una voluntad definida y racional respecto a las cuestiones singulares y que elige sus representantes esperando que estos pongan en práctica esa voluntad. La elección de los representantes se considera el fin que se subordina al fin primario del sistema democrático que consiste en brindarle al electorado el poder de decidir en las controversias políticas.

Schumpeter propone revertir ese orden para pensar la democracia. En primer lugar se produce la elección de los representantes que efectúan las decisiones y, en segundo lugar, la decisión de las controversias por parte del electorado. El papel del pueblo es crear un gobierno. La definición de democracia que propone la teoría clásica debería ser repensada en estos términos: "Método democrático es aquel sistema institucional para llegar a las decisiones políticas en el que los individuos adquieren el poder de decidir por medio de una lucha de competencia por el voto del pueblo" (Schumpeter, 1984: 334).

La propuesta de Schumpeter otorga, según su propio autor, una serie de ventajas que permiten una mejor comprensión de las democracias reales. Entre esos beneficios se destacan la capacidad de distinguir entre regímenes democráticos de aquellos que no lo son, aunque representen cierta "voluntad general" de reconocer que la voluntad de la mayoría no es sinónimo de la voluntad del pueblo y que los grupos tienen voluntades particulares, que necesitan de un líder para convertirse en un factor político. Incluso, esta nueva definición permite identificar la presencia del caudillaje político (ignorado por la teoría clásica) en los regímenes democráticos y advertir que la competencia por ese caudillaje puede comprenderse en términos similares a la competencia económica. El principio de la democracia es entregar el gobierno a la persona o grupo con mayor apoyo electoral respecto de sus competidores, asegurando la permanencia del sistema de mayorías dentro de la lógica del método democrático. A su vez, Schumpeter señala que en esa misma lógica de mercado, los deseos del pueblo no fluyen de su propia iniciativa. Son configurados y su configuración es una parte esencial del proceso democrático. Los electores no deciden problemas pendientes sino que la iniciativa radica en el ofrecimiento del candidato, resultando o no aceptada por el electorado. 
Los partidos y los agentes electorales de partido, son simplemente la respuesta al hecho de que la masa electoral es incapaz de otra acción que la estampida y representan un intento de regular la competencia política de una manera exactamente similar a las prácticas correspondientes de los asociados, de comerciantes... La psicotecnia de la dirección de un partido y la propaganda de partido, las consignas y las marchas musicales, no son simples accesorios. Son elementos esenciales de la política. También lo es el boss (cacique) político (Schumpeter, 1984: 334).

\section{La competencia por el caudillaje en el espacio público mediatizado}

Una vez reconstruida sintéticamente la propuesta de Schumpeter, buscaremos comprender algunos aspectos de su teoría desde su dimensión discursiva. Recurriremos a diferentes estudios que intentan comprender la relación entre comunicación y política, a los fines de analizar el funcionamiento de la competencia por el caudillaje y sus actores a partir de sus prácticas discursivas. La pertinencia de la inclusión de esta dimensión de análisis está fundamentada principalmente en dos razones. En primer lugar, la exposición del propio Schumpeter incluye elementos comunicacionales para describir la contienda que supone el funcionamiento democrático: argumentos, propaganda, persuasión, sentidos, efectos, psicotecnia, consignas, entre otros. Todos estos conceptos han sido largamente discutidos por diferentes corrientes teóricas de la comunicación. Por otra parte, existen numerosas investigaciones que reconocen la estrecha vinculación entre comunicación y política, coincidiendo en que esta última es afectada y transformada por la primera. De allí surgen conceptos como "Política virtual", "Videopolítica", "Marketing político", entre otros. Cada uno de ellos propone un vínculo diferente entre estas dos entidades. No obstante, prevalece cierta mirada canónica que atribuye a la comunicación el provocar la espectacularización de la política y su consecuente degradación. Sin embargo, propondremos aquí comprender la relación a través de la noción de "mediatización de lo político" (1) que busca trascender el juicio normativo y analizar el fenómeno desde su complejidad.

Uno de los aspectos en el que creemos conveniente indagar es el escenario en el que tiene lugar la competencia por el caudillaje. Aquí diremos que gran parte de la contienda se dirime en el espacio público (2). Entendemos el espacio público como un lugar de relación, de experiencia, de acción; un espacio disponible para el encuentro, abierto a todos -primer sentido de público como accesible a todos- en el que se dirime un orden común -segundo sentido de público como lo que es común a todos (Peñamarín, 2008)-. En esa contienda por establecer un 
universo común es, a nuestro entender, donde se resuelve la competencia por el caudillaje. El triunfo de un candidato en una contienda electoral no puede explicarse sin tener en cuenta su triunfo en la lucha por imponer ciertos objetos en el orden de lo común e imponerse como sujeto capaz de designar esos objetos, atribuirles significación y argumentar al respecto. La tarea del político que aspira al caudillaje consiste en la delimitación de un nosotros, esto es, un colectivo de identificación que se rige por ciertos valores, creencias e ideas compartidas que sostienen al caudillo como legítimo intérprete y portavoz. El establecimiento de significados comunes es siempre una tarea conflictiva. La actividad política se nos presenta como constitutivamente polémica, en cuanto siempre enfrenta a uno o más adversarios. Profundizaremos este aspecto más adelante.

A partir de que hemos propuesto al espacio público como escenario de la competencia por el caudillaje y enmarcado esta contienda en la lucha por el establecimiento de un orden común, intentaremos reconstruir cómo se libra esa competencia en sociedades mediatizadas, caracterizando el rol de los políticos, los ciudadanos y los medios de comunicación.

Como hemos mencionado anteriormente, la creciente influencia de los medios sobre la política es en la gran mayoría de los casos observada como negativa, otorgando a los primeros el estatus de factor causal de cierta espectacularización de la política. La política es subsumida por la televisión y de esta manera despojada de su principio racional para ser gobernada por la imagen y las pasiones. Se observa una degradación de la praxis política al ser vaciada de sus contenidos. La lectura de Giovanni Sartori (1998) respecto de la fuerza arrolladora de la imagen cuyos efectos no son más que la destrucción de procesos cognitivos necesarios para el desarrollo de una opinión pública racional ha dado origen a múltiples investigaciones que siguieron su lógica argumental. Lo que subyace a la mayoría de estas interpretaciones es el ideal de la política como praxis racional. Sólo los argumentos a los que se puede acceder por la vía de la razón son genuinos de la esfera política. Las emociones, sentimientos, pasiones, que se adhieren a los comportamientos políticos son factores exógenos, que corrompen su ideal funcionamiento.

Las ideas de Schumpeter que describimos anteriormente, se manifiestan contrarias a estas apreciaciones. Para el economista austríaco, los individuos que participan en política no son sujetos cuyas acciones están unívocamente determinadas por la razón. Tampoco existe un bien común racional que oriente la voluntad general. Sino que esa voluntad es producto del accionar de los grupos que aspiran al poder político. En su construcción, aunque en ocasiones se apela a la argumentación racional, por lo general imperan recursos que movilizan los sentimientos y las emociones. Por lo tanto, aquellos argumentos que entienden que los medios 
introducen factores exógenos no racionales en la política y que a estos se debe su degradación, pierden sustento cuando notamos que aquellos no son ajenos, sino constitutivos de su propia práctica. La reflexión en torno al vínculo entre las emociones y el habla pública tiene antecedentes en las primeras reflexiones sobre el problema de la discursividad (Bermudez, 2014). En El arte de la retórica Aristóteles rechazaba la distinción categórica entre logos y pathos en la acción persuasiva, negándose a considerar a la emoción como patología discursiva, sino más bien reconociéndole a la capacidad de conmover la eficacia necesaria para suscitar una convicción. No obstante esta postura forma parte de un debate extendido a lo largo de toda la historia de la retórica que fue trasladado a las actuales teorías de la argumentación.

Desde la teoría pragma-dialéctica se considera la emoción como un factor de infiltración de lo irracional, una fuente de error tratada en el campo de las falacias que violan las reglas de la discusión crítica. Por el contrario, desde el análisis de la argumentación en el discurso se rechaza la concepción patogénica de la emoción aceptando que existe una conexión estrecha que liga la emoción con la racionalidad.

Así pues, lejos de ser una energía salvaje, la pasión es solidaria con la razón: la primera se manifestaría como una construcción de sentido y una actitud que conllevan, por obra de la tradición, una cultura e inteligencia inherentes; recíprocamente, la segunda demostraría estar inficionada por las pasiones que dice combatir. Esta idea debería, asimismo, morigerar tanto la demonización de las pasiones como la exaltación de la razón (Bermúdez, 2014: 18).

Esto no significa que los medios no ejerzan ningún tipo de efecto transformador sobre la política. Sin embargo, lo que debemos dejar en claro es que cuando nos referimos a la mediatización de la política no estamos haciendo referencia a que esta última ha devenido en pura dramaturgia a causa de la colonización mediática. En efecto, la relación entre política y espacio público, terreno en el cual hemos emplazado la lucha por el caudillaje, siempre estuvo marcado por la lógica de la puesta en escena. Al inscribirse en el espacio público la acción política siempre constituye un régimen de visibilidad. Con o sin mediatización, la política "es espectacular en un sentido originario: no sólo instituye un adversario sino que funda, por la fuerza de su aparición un espectador" (Cingolani y Fernández, 2010) y ello tiene sus consecuencias en el plano discursivo, y por lo tanto en la forma en que se libra a competencia por el caudillaje. Si a partir de Carl Schmitt (1991) observamos como constitutivo de la política la distinción de amigo/enemigo y por ende su dimensión polémica, debemos agregar que no puede existir un ellos y un nosotros sino para un espectador frente al cual se polemiza. La competencia por el caudillaje no sólo se libra como un enfrentamiento bipolar entre dos 
adversarios, sino que también siempre debe considerarse la presencia de un tercero como constitutivo de la escena. Se trata de la dimensión espectacular de la política. Ese tercero, en el plano discursivo, opera como "principio regulador de las condiciones de producción del discurso político en el espacio público" (Cingolani y Fernández, 2010).

Por lo tanto, si la dimensión espectacular es constitutiva de la competencia por el caudillaje, aún resta saber cuáles son las consecuencias de su mediatización. Lo que Cingolani y Fernández proponen es que la mediatización provoca una "ruptura de escala" (3). Es la escala del espectáculo lo que se modifica y no su naturaleza. Lo distintivo del fenómeno es que se sucede una transferencia a nivel colectivo de operaciones de significación que anteriormente solo se podían dar a nivel interindividual. Si la política siempre supuso una puesta en escena en el espacio público, la mediatización introduce una segunda instancia de puesta en escena, modificando el régimen de visibilidad de la discursividad política. El desafío que la mediatización presenta a los políticos es articular las tensiones entre dos lógicas de construcción de regímenes de visibilidad diferentes. Por una lado las inscripciones de acciones colectivas en el espacio público -que los políticos dominan con facilidad- y por otro, la mediatización de esas misma acciones que lo desplazan hacia escenarios donde la puesta en escena les es más difícil de controlar.

Por otra parte, la mediatización da origen a un nuevo actor que a nuestro entender será clave en la competencia por el caudillaje: el periodismo (4). Como institución emergente del proceso de mediatización y fundada en dispositivos tecnológicos como sistema diferencial, establece una relación -ya sea de intermediación, de constitución o de contacto- privilegiada con ese tercero espectador de la contienda política. El periodismo puede intervenir sobre el principio regulador de la discursividad política (Cingolani y Fernández, 2010). Esto permite explicar la permanente conflictividad existente entre los actores políticos y los medios de comunicación. La historia reciente de nuestro país es una clara evidencia de estos enfrentamientos, en los cuáles los medios masivos les disputan a los políticos la capacidad de construir una escala de prioridades en el espacio público.

\section{El lugar de las mediaciones en la competencia por el cuadillaje}

Pensar en los medios como intermediarios entre los políticos y sus públicos nos conduce a indagar sobre otro aspecto de la propuesta de Schumpeter en el que creemos conveniente profundizar: la creación de voluntades a mediante artificios técnicos a disposición de los grupos 
de interés. Una de las hipótesis de Schumpeter acerca del funcionamiento de la competencia por el caudillaje consiste en que los competidores moldean la voluntad de los electores según sus propios intereses. La voluntad de los electores no es preexistente a la acción de los aspirantes a caudillo sino que es un producto de ella. En este punto se hace evidente la influencia weberiana en el pensamiento de Schumpeter (Rodríguez Arechavaleta, 2007). Para Weber el político es autorresponsable, en el sentido en que no debe seguir ningún tipo de indicación más que sus propias convicciones para las cuales buscará apoyo parlamentario y electoral. La iniciativa reside únicamente en el político, sin necesidad de compartirla con nadie. Esto difiere de las ideas clásicas criticadas por Schumpeter, según las cuales el político debe gobernar de acuerdo a la voluntad general.

Su autoridad ante las masas y sus partidarios no se basa en los objetivos concretos, sino en sus cualidades personales; no es su hombre de confianza, sino su señor, a quien a través del acto electoral, se entregan incondicionalmente por el tiempo de duración de su mandato, pues no es la masa "pasiva" la que da a luz al conductor, sino que es éste el que procura atraer a sus partidarios y obtiene el favor de la masa a través de la 'demagogia' (Rodríguez Arechavaleta, 2007: 8).

El propio Weber denuncia la "pérdida del alma" de los seguidores de líder plebiscitario, reconociendo que bajo su dirección se produce una "desespiritualización" de los partidarios, una proletarización espiritual. Los seguidores obedecen ciegamente al caudillo hasta convertirse en una máquina, sin pretensiones de tener opinión propia, ni sentirse perturbados por vanidades de notables (Rodríguez Arechavaleta, 2007).

Sin embargo, entendemos aquí que ese poder manipulador que Schumpeter le otorga a los caudillos para manipular a su antojo la voluntad de sus seguidores debe ser matizado. Observamos que la capacidad atribuida al líder político para crear voluntades según su propio interés radica en cierta desconexión de la competencia por el caudillaje de la dimensión cultural que la atraviesa. Nuestro acceso al mundo, y por ende a la propia competencia por el caudillaje, está mediada por el lenguaje, la cultura, los géneros, los sistemas simbólicos que organizan el sentido desde el que categorizamos, sentimos, percibimos y comprendemos. Esa mediación nos conduce a pensar que toda acción que los políticos realizan en pos de erigirse como caudillos sólo tendrá relevancia si logra enmarcarse o traducirse en el sistema articulado de significados en el que el sujeto receptor está inscripto. La mediatización en la que emplazamos la lucha por el caudillaje "tiene en cuenta a los sujetos en cuanto receptoresintérpretes que activan ciertos sistemas previos de comprensión e interpretación, es decir, 
sujetos situados cultural y socialmente, dotados de tradiciones (siempre, en algún modo, híbridas y plurales), intereses, relaciones, mundos de vida" (Peñamarín, 2008). Es decir que la propia competencia queda mutilada si se ignoran aquellos procesos mediante los cuales los sujetos traducen, adaptan, transforman los productos comunicacionales de los candidatos desde sus intereses y culturas para así incorporarlos a su vida cognitiva, imaginativa y práctica, en un proceso en el que se transforman también a sí mismos.

Para comprender este aspecto creemos conveniente recurrir a una categoría conceptual proveniente de las ciencias de la comunicación que ha sido clave para ilustrar el devenir de los discursos mediáticos en las sociedades modernas. La noción de mediaciones propuesta por Jesús Martín-Barbero para analizar cómo los medios incorporan la cultura de sus públicos en sus productos comunicacionales y cómo las audiencias elaboran sus recursos culturales a partir de la oferta mediática puede resultar de gran utilidad para la comprensión de la lucha por el caudillaje, evitando la lectura de una ciudadanía pasiva y manipulable al antojo de los grupos de interés. En las prácticas discursivas de los aspirantes a caudillos hablan también sus destinatarios. Sus discursos son el producto de la negociación entre la propia lógica del sistema electoral (cuyo régimen se asemeja a lógica comercial-publicitaria) y la heterogeneidad cultural de los mundos sociales de la ciudadanía. Los políticos se convierten en intérpretes de sus públicos, interesados en traducir sus preferencias y mundos de vida. Los ciudadanos, por su parte, configuran comunidades hermenéuticas a partir de las diversas competencias culturales que atraviesan los haberes y saberes, los imaginarios y las memorias de los varios sectores sociales (Peñamarín, 2008).

De esta manera nos permitimos poner en duda la afirmación de Schumpeter respecto a la creación de voluntades por el designio individual del aspirante a caudillo. La estrategia de estos últimos para erigirse como líderes políticos supone una negociación con los universos sociales y culturales de los ciudadanos. No obstante, debe reconocerse que no es una negociación entre iguales, sino que los competidores por el caudillaje (algunos más que otros) tienen una posición de privilegio para la configuración de los sistemas de sentido que orientan las lecturas de los discursos que forman parte de la contienda. En este aspecto, a su vez, es donde los políticos entran en competencia con los propios medios de comunicación debido a la influencia que estos últimos tienen en la construcción de universos interpretativos que configuran las prácticas, los valores, los afectos, los vínculos e implican relaciones de poder.

\section{Discusión}


Comprender el modo en que se desarrolla la competencia por el caudillaje político en las democracias contemporáneas implica reconocer su inscripción en el sistema sociocultural que la contiene y le otorga sentido. De esta manera, la actualidad se caracteriza por el florecimiento de múltiples espacios regidos por diferentes sistemas de sentido y valor. Estos afectan la constitución de lugares comunes a partir de la cual los sujetos elaboran su experiencia y por ende, tienen un impacto directo en la lucha por el caudillaje. Los lugares que tradicionalmente fueron eje de la configuración de identidades están siendo desplazados por sistemas deslocalizados. La competencia por el caudillaje se proyecta hacia nuevos escenarios mediatizados. El surgimiento de nuevos sistemas de comunicación como las redes sociales en internet nos interpelan a buscar comprender cómo, a partir de una nueva mediatización, surge y eventualmente se consolidan corrientes y comunidades interpretativas que pueden dar lugar a la conformación de una colectividad. Cabría preguntarse entonces cómo se relacionan esas formas mediatizadas de vinculación y diferenciación con el orden de lo político en el actual contexto comunicativo en el que conviven innumerables regímenes de significación. Resulta imprescindible una reflexión que examine los tipos de representaciones que producen estas diversas materialidades significantes. En las diferentes mediatizaciones se producen universos de sentido que, no obstante, actúan en simultaneidad produciendo niveles inéditos de complejidad social (Valdettaro, 2007). En este marco de complejidad es que se inscribe la lucha por el caudillaje.

Por otra parte, creemos necesario intensificar el debate acerca del creciente clima de conflictividad en la vida política argentina. La propuesta de Schumpeter de comprender la democracia como una competencia implica pensar que la actividad política inaugura un espacio polémico, donde los participantes se disputan la hegemonía, entrelazados a las estructuras de poder de las que participan. Esa disputa se convierte en un factor de exclusión en la medida en que los ciudadanos participan en procesos de cierre y reafirmación de sus propias colectividades y buscan imponer sin reparos aquellos valores e ideas que consideran innegociables. Las colectividades establecen a menudo signos discriminatorios innegociables (Peñamarín, 2008), estableciendo límites a su territorio que demarcan lo aceptable e inaceptable para formar parte. Si bien las fronteras se negocian y pueden variar, también se observan procesos de fijación y discriminación identitaria. En ese proceso siempre intervienen factores emocionales. Estos deben ser considerados imprescindibles para comprender el funcionamiento de la competencia por el caudillaje en cada sistema democrático dado que su 
presencia puede contribuir a la formación de distancias irreconciliables entre diferentes colectivos de ciudadanos.

En este sentido sería interesante intentar una aproximación al modo en que el sentido social interviene en el funcionamiento y la regulación de las emociones individuales. En otras palabras, explorar el punto donde el procesamiento grupal de las emociones que se configura, entre otros espacios, en la lucha por el caudillaje se intersecta con el comportamiento individual.

\section{Notas}

(1) El término mediatización de la política tiene como precursor el advenimiento de un conjunto de diagnósticos que caracterizan a la sociedad contemporánea como "mediatizada" o en "vías de mediatización". En líneas generales, se intenta dar cuenta de "la adaptación de las instituciones de las democracias industriales a los medios, que se transforman en los mediadores insoslayables de la gestión de lo social" (Verón, 2004: 225). La mediatización implicaría una "influencia de los medios de comunicación sobre los mecanismos de funcionamiento social" (Verón, 1997).

(2) No debemos dejar de mencionar la centralidad lo secreto en la vida política (Bobbio, 2009), principalmente en el ejercicio del gobierno pero también en la lucha por acceder al poder. Aquí haremos énfasis en la competencia pública por el caudillaje dejando de lado aquello que se mantiene oculto a la ciudadanía.

(3) La idea de los medios como "dispositivos de ruptura de escala" proviene de las hipótesis de Eliseo Verón (2001) acerca de la mediatización y la inauguración de múltiples regímenes semióticos.

(4) Aquí podríamos incluir al conjunto de quienes son considerados "formadores de opinión pública", que va más allá de aquellos profesionales considerados "periodistas" en su versión más tradicional.

\section{Bibliografía}

Bobbio, N. (2009). Teoría general de la política. Madrid: Trotta

Cingolani, G. y Fernández, M. (2010). Televisión y política: espacio público, puestas en escena y regímenes de visibilidad. Revista Oficios Terrestres, 25, 37-49.

Peñamarín, C. (2008). ¿Hay vida política en el espacio público mediatizado? ClC. Cuadernos de Información y Comunicación, 13, 61-78.

Rodriguez Arrachavaleta, C. (2007) Redefiniendo la democracia. Los orígenes de la democracia competitiva: J. Schumpeter. Revista de Ciencias Sociales de la Universidad Iberoamericana. Recuperado de http://www.redalyc.org/articulo.oa?id=211015576010 
Sartori, G. (1998). Homo videns. La sociedad teledirigida (La opinión teledirigida). Madrid: Taurus.

Schmitt, C. (1991). El concepto de lo político. Madrid: Alianza.

Schumpeter, J. (1984). Capitalismo, socialismo y democracia. Buenos Aires: Sarpe.

Verón, E. (1997). Esquema de análisis para la mediatización. Revista Diálogos de la comunicación, 48, 9-16.

Verón, E. (2001). El cuerpo de las imágenes. Buenos Aires: Norma.

Verón, E. (2004). Los medios en recepción: desafíos de la complejidad. En Fragmentos de un tejido. Barcelona: Gedisa. 